\title{
Statistical energy analysis model for sound pressure level prediction on refrigerators
}

\author{
R. Zárate*1, J. Poblet-Puig ${ }^{\dagger 2}$, M. Ortega ${ }^{\ddagger 3}$ and M. López-Parra ${ }^{\S 1}$ \\ ${ }^{1}$ Unidad de Alta Tecnología, Facultad de Ingeniería, Universidad \\ Nacional Autónoma de México \\ ${ }^{2}$ Laboratori de Càlcul Numèric, E.T.S. d'Enginyers de Camins, Canals \\ i Ports de Barcelona, Universitat Politècnica de Catalunya \\ ${ }^{3}$ Department of applied physics, Mabe TyP, Jurica, Querétaro, \\ México.
}

September 10, 2020

\begin{abstract}
A Statistical Energy Analysis (SEA) model of a 510 liter capacity refrigerator is used to calculate the Sound Pressure Level (SPL) generated in a reverberation room. This is a reliable indicator of the vibroacoustic performance of the refrigerator and it is in some countries as a pre-commercialization test. The main contributions of the SEA model are, the characterization of the refrigerator structure (three-layer: HIPS, polyurethane foam and steel), and the modeling of important components such as internal chambers or ventilation gratings. The simulation results are successfully compared with laboratory measurements. The SEA model is then used to understand the vibroacoustic behavior of the refrigerator and to establish the most critical transmission paths and radiation mechanisms.
\end{abstract}

\section{Introduction}

The amount of noise generated by home appliances in a kitchen is a factor increasingly taken into account by customers. A disturbing sound may be associated with low quality, while a pleasant sound can be related to a premium quality of a product,

*correspondence: UNAM, Fray Antonio de Monroy e Hijar 260, Juriquilla, Querétaro, 76230 México. e-mail: r.zarate7143@gmail.com

${ }^{\dagger}$ correspondence: UPC, Campus Nord B1, Jordi Girona 1, E-08034 Barcelona, Spain. e-mail: jordi.poblet@upc.edu

${ }_{\ddagger}^{\ddagger}$ e-mail: martin.ortegabrena@gmail.com

§e-mail: lopezp@unam.mx 
resulting in customer satisfaction. Noise generation does not only determine the selling success of a product, but it can even prevent the device from being sold if it does not satisfy the noise regulation standards. The standards for maximum allowed noise emissions for household refrigerators are becoming more strict over time. They tend to limit the overall Sound Pressure Level (SPL) emitted by the device in a frequency range from 100 to $10000 \mathrm{~Hz}$. As an example, the European Union (EU) has included the mandatory declaration of the sound power level of household appliances [31, 17], where a maximum of $40 \mathrm{~dB}$ is set to obtain the current EU Ecolabel for cold appliances under the standard EN 60704:2014 [2]. In other countries where there is a lack of formal regulations for appliance noise levels, the market requirements are dictated by the different competing manufacturers. For the US market, it is common to do a baseline noise measurement of competing units and setting a goal to be below average or 'best in class' product, allowing for marketing claims regarding the low noise level.

Several researchers have performed studies to determine which home appliances have the largest contribution to noise in a kitchen, where the refrigerator is identified as the biggest noise contributor [20]. Also the SPL of various types of refrigerators have been investigated and reported using an anechoic chamber and measured in some apartments [34]. Moreover, the fridge is the only appliance that operates all day long.

\subsection{Goals and contributions of the research}

This paper presents a model of a refrigerator (with a capacity of 510 liters). The generated noise level must be simulated in the frequency range between 100 and $10000 \mathrm{~Hz}$. A model based on Statistical Energy Analysis (SEA) is proposed. The inputs of the model are characterised experimentally: acoustic and mechanical power of compressor, evaporator fan and condenser fan. The predicted noise is validated in a reverberation room under the standard ISO-3741. Afterwards, the SEA model is used to provide some design guidelines for quieter refrigerators that satisfy the noise specifications proposed by international standards.

The goals that needed to be covered and the contributions provided by this research can be summarised as follows:

1. Development of the SEA model. It must be able to account for the refrigerator and the reverberation room where the regulation test is performed. In addition of the noise emissions of the refrigerator, the model should be able to provide information on the energy distribution and sound transmission path.

2. The measurement of the loss factor (sound absorption coefficient) for the multilayered elements. This was carried out using the impedance tube method.

3. Estimation of the Coupling Loss Factor (CLF) for the bending vibration transmission at structural junctions (L, T and X-shaped) of multi-layered material. This is composed of three different materials (HIPS, polyurethane foam and steel). Most of the models reported in the literature restrict the study of vibration transmission to junctions formed of homogeneous plates at each of their parts. 
4. Validation of the SEA model with experimental data.

5. Determination of the influence of grommets (rubber vibration isolators) in the overall vibroacoustic response of the refrigerator.

6. To learn some aspects related with material characterisation, dominant paths, design aspects that have more influence on the overall noise emission. They can be used as pre-design information for other refrigerator models or to have some reference values for the material data.

\subsection{Overview of modelling and design of home appliances}

The refrigerator acoustic design is an iterative process. The knowledge obtained from the model predictions can be used to improve the prototypes. But the models must be fast enough to make this interaction with the industrial production possible. At the same time, they must be able to account for the key aspects that determine the acoustic response and to provide answers in the whole frequency range (100 - 10000 $\mathrm{Hz}$ ). The Statistical Energy Analysis (SEA) is a very adequate technique since it is valid for mid and high-frequency noise (large number of waves and high modal density), which corresponds to our frequency range of interest. It is difficult to solve the problem with FEM and CFD at this frequencies with reasonable computational times.

SEA is a high-frequency technique described by Lyon [25, 22], which has been used to model and simulate the behaviour of dynamic systems. It can also include experimental information from the laboratory measurements without major difficulties. Modal density, loss factor and coupling loss factor are some the main experimental SEA parameters needed to develop a model, which can be obtained using different type of test. The modal density measurement for shells has been carried out by vibration testing and derived assuming that the modal density of the shell would be equal to the sum of modal densities of the shell [10]. The power input method (PIM) [9], has been employed for determining the loss factor of plates using the impact hammer excitation and several accelerometers to record the response over the plate.

A typical application of this technique is the modelling of acoustical performance of complex material plates, calculating the STL (Sound Transmission Loss) of sandwich panels [39] using the equations based of the SEA combined with the equations of motion of the sandwich panel, obtaining good agreement with the experimental data for two type sandwich plates, on a range from 100 to $10000 \mathrm{~Hz}$. Another application is to find optimum damping factors for structural subsystems in order to control the power flow of a system [24].

SEA has been applied in the aerospace industry [14, 28], predicting the structural vibration levels and the structure-borne noise radiated inside a cabin. In the automotive industry [29], to predict noise radiated inside a vehicle in the frequency range from 500 to $6300 \mathrm{~Hz}$. On later design stages, SEA analysis is used to predict the structural response and acoustic power radiated by a ship [8], calculating the coupling loss factor between shell and heavy fluid added mass, obtaining a prediction in the frequency range from 100 to $500 \mathrm{~Hz}$. SEA has also been used in the railway industry [13], modelling the interior field of a railway vehicle with five cavities connected by 
openings, forming a series of coupled air cavities and validating on a 1:5 scale model, achieving good prediction in the octave bands from 500 to $4000 \mathrm{~Hz}$.

An application of SEA to the household appliances industry is shown with a methodology to identify the noise and vibration source on a frontloaded washer-dryer machine [7], using a SEA model of a panel and a review of different materials for effective noise mitigation. SEA has also been used in a refrigerator to predict the SPL of the mechanical assembly of the evaporator fan. In [40], a good correlation between SEA predictions and experimental data is obtained. However, to achieve noise reduction on a full refrigerator using SEA, it is necessary to take in account all sources and mechanical structures of the refrigerator. The information presented up to here demonstrates that SEA is not the best modeling technique to apply in the low frequency range, where FEM or BEM are better techniques, however, the regulations [2] do not consider the low-frequency noise in the output parameters.

In the remainder of the document, the SEA model and methods considered to simulate the refrigerator response are described in Sect. 2. The experimental measures are used to obtain input data for the SEA model. The results of Sect. 3 include the validation of the model and its application in order to understand the vibroacoustic behaviour of the fridge and improve the vibroacoustic response.

\section{Methods: Description of the SEA model}

A description of only those modeling aspects which are specific for the refrigerator is done here. For a full explanation of the SEA theory (hypotheses, steps of the process, equations etc.) we refer to some books in the literature [25, 22]. First, a detailed overview of the model is done in Sect. 2.1. For the parts of the fridge that can be modeled as an idealised element (i.e. rectangular plates or cubic-shaped acoustic cavities), standard state-of-the-art SEA formulas are considered and the description is done just by providing basic references. However, for other more complex parts that are more specific of this case study the detailed formulation is provided.

Other aspects such as some complex element which determines the acoustic response of the fridge are described in Sect. 2.3. The parameters are obtained from specific laboratory experiments of the components.

The power inputs for the SEA model were derived from the experimental measurements of sound pressure and vibration of each source of the refrigerator (compressor, condenser fan and evaporator fan), performed in a semi-anechoic chamber. The sound power of the sources is characterized according to the regulation ISO-3745 [19]. The measurement locations of the SPL are distributed at ten positions on a hemispherical surface surrounding the source, placing a microphone (B\&K Type 4189) on each of the measurement positions. Experimental data was collected on a range from 100 to $10000 \mathrm{~Hz}$ with a time averaging of 32 seconds and processed with a data acquisition system using independent channels for sound pressure and acceleration. The results are used to compute the power input, assuming that the sound field in the source and the receiving room are diffuse [18]. The inputs are associated to subsystems 24 and 25 described in Sect. 2.1, where the sources are located. The characterization of the structural power generated by each source was carried out using the two stage 
reception plate method [15]. The first stage is the measurement of free velocities over the source contact points based on the Standard method ISO 9611 [5]. The sources were suspended with several elastic ropes placing several accelerometers (B\&K Type 4525 ) on the contact points where the sources couple with other subsystems ( 4 for the compressor and 2 for the evaporator and condenser fan). The second stage involves the reception plate method (RPM) [36], and it is used to quantify the structure-borne sound power of sources with any number of contact points, referred to in the Standard EN15657-1 [1]. Once the experimental free velocities and mobility data at the link points of sources is obtained, the inputs for mechanical power can be computed and associated for subsystems 17 and 19 described in Sect. 2.1, where the sources are attached to the receptor subsystems by means of joints that represent the grommets (resilient contact points) [32]. The formulas for the receiver point mobilities at the side and the transfer mobilities of the connecting tie with grommets are provided in [26]. The three different sources are characterized independently. The tests were carried out at a compressor rotation speed of $3600 \mathrm{rpm}$, the condenser fan at $2500 \mathrm{rpm}$ and the evaporator fan at $2650 \mathrm{rpm}$.

\subsection{Subsystems definition}

A first step is to identify the refrigerator parts that can be considered as a SEA subsystems. This is not a straightforward task because it is a vibroacoustic system that contains an important number of geometric details. The decision is at the same time not unique and there is more than one way to define the subsystems.

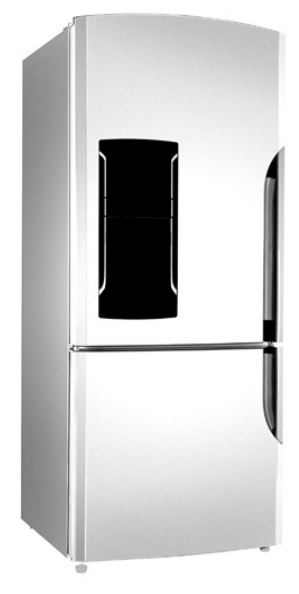

a)

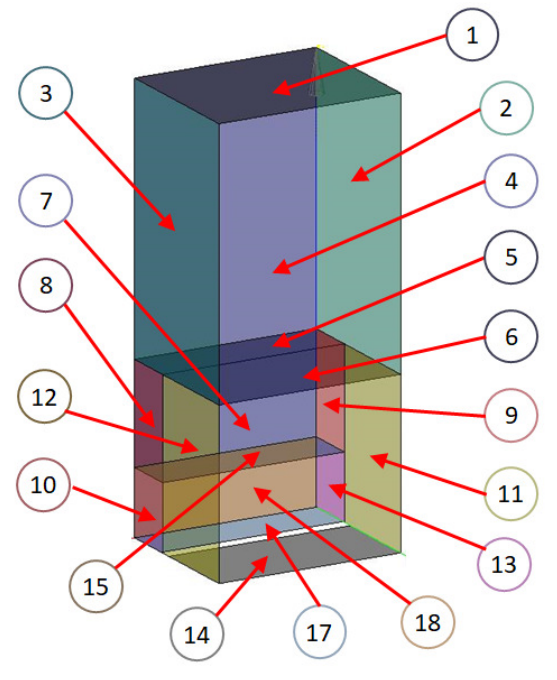

b)

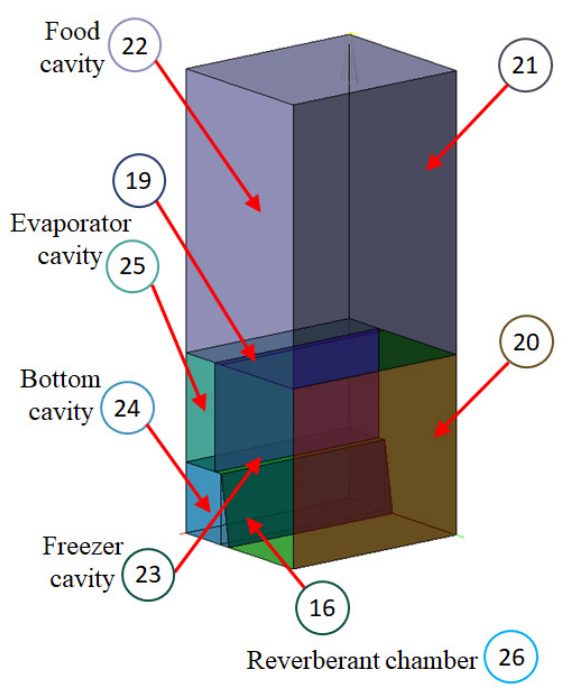

c)

Figure 1: Subsystem definition of the fridge structure: (a) Photo of the fridge, general view; (b) subsystem definition, structural parts; (c) subsystem definition, inner cavities.

The subsystems definition considered in this analysis is shown in Fig. 1. The SEA model has a total of 26 subsystems, including the reverberation room. It is based on SEA subsystems of two different types: plates and acoustic cavities. For the plate type 
subsystems, only the bending behaviour is considered. The results will corroborate that this is a correct modelling decision because the structural path is not the most critical one. In this case, there is no need to increase the complexity of the SEA model in the description of the structural vibration (for example to use a different definition of the subsystems or include other wave types). The SEA parameters required for the model computation are the modal density, the bending wave speed, the bending wave number, the bending wavelength, the damping loss factor, and the critical frequency. For the acoustic cavities the parameters are the modal density, the volume and the total area.

The cabinet body is divided into 18 structural subsystems. These are rectangular plates with three different material layers: HIPS, polyurethane foam and steel. The multilayer plates will be modelled as a single subsystem. The evaporator is labelled with the subsystem number 19 in the Fig. 1(c) (which is the structure where the evaporator fan is located), the rear base indicated with the subsystem number 17 in the Fig. 1(b) (where the compressor and condenser fan are placed) and the access cover are modeled as thin plates. A total of 21 structural subsystems are considered. Two of these subsystems, the rear base and the evaporator structure are subjected to mechanical excitation by means of a point force that generates an input power to the SEA model.

The refrigerator has four interior cavities: fresh food cavity (subsystem number 22 ); bottom cavity (subsystem number 24) that contains two sources, the compressor and condenser fans; two freezer cavities connected by an opening representing the suction and discharge air zones with subsystem numbers 25 and 23 respectively (it contains the evaporator fan as source). Each of these four cavities is considered as a SEA subsystem. In the tests, the refrigerator is placed inside a reverberation room which is also considered an acoustic cavity.

The plates indicated with subsystem numbers 5 and 6 , are those elements that separate the food cavity from the freezer cavity and evaporator cavity respectively. The evaporator cavity and freezer cavity are separated through a common plate indicated with subsystem number 19. The plate number 15 separates the bottom cavity from the evaporator cavity, while the plate number 16 separates the bottom cavity from the freezer cavity.

\subsection{Connections between subsystems}

For the vibration transmission through the structural junctions, the formulas for bending wave transmission through $\mathrm{L}, \mathrm{T}$ and $\mathrm{X}$ junctions provided in [12] are considered. It implies the assumption that the three-layer plates behave as a single plate. The homogenised elastic properties are computed as proposed in [25]. The total bending rigidity at high frequencies can be obtained as the sum of the real parts of bending rigidity of the top $\left(B_{1 r}\right)$ and bottom $\left(B_{3 r}\right)$ plates

$$
B_{r} \simeq B_{1 r}+B_{3 r}
$$

The coupling between the acoustic cavities and the plates is done as described in $[12,18]$ with the radiation efficiencies computed as 


$$
\sigma_{\text {rad }}= \begin{cases}\frac{U c_{0}}{4 \pi^{2} f^{1 / 2} f_{c}^{1 / 2} S\left(\mu^{2}-1\right)^{1 / 2}}\left[\ln \left[\frac{\mu+1}{\mu-1}\right]+\frac{2 \mu}{\mu^{2}-1}\right] & \text { if } f<f_{c} \\ {\left[\frac{2 \pi f}{c_{0}}\right]^{1 / 2} l_{x}\left[0.5-0.15 \frac{l_{x}}{l y}\right]} & \text { if } f=f_{c} \\ {\left[1-\frac{f_{c}}{f}\right]^{-1 / 2}} & \text { if } f>f_{c}\end{cases}
$$

In Eq. (2),

$$
f_{c}=\frac{c_{0}^{2}}{2 \pi}\left[\frac{\rho_{S}}{B_{r}}\right]^{1 / 2}
$$

is the critical frequency of the plate, $U$ is the perimeter of the radiating area, $c_{0}$ is the speed of sound, $S$ is the plate surface, $l_{x}$ and $l_{y}$ are the plate dimensions, $\rho_{S}$ is the surface density and $\mu=\left(f_{c} / f\right)^{1 / 2}$.

A fundamental part of the fridge model is how to represent the compressor cavity of Fig. 2(a). On the one hand, it contains two important sources of sound and vibration: the compressor and the condenser fan. They generate sound inside the cavity but also introduce vibration to the fridge's structure through the rear base (subsystem number 17), at which both sources are physically linked. On the other hand, several transmission paths from the compressor cavity to the reverberation room exist from the compressor cavity: to the exterior through the ventilation grating that is shown in Fig. 2(a-c); to the exterior through the existing slit between the base plate and the fridge structure; to the exterior due to the vibration of the plate grating; and the transmission of vibration to the fridge structure.

The sources in the compressor cavity are represented in Fig. 3. Both the compressor and the condenser fan are modeled by means of an acoustic point source and point forces. The acoustic point source is exciting directly the acoustic cavity. The point forces are exciting a single receiver subsystem, as it is modeled in [27, 35]. For this case both vibration sources are linked to the rear base plate by means of springs. The springs represent the legs sustaining the devices and the grommets used to attenuate the vibration transmission. A sketch is provided in Fig. 3(b). The quantification of the acoustic power of the sources, the vibration power introduced in the structure and the attenuation caused by the grommets is done by means of experiments.

The transfer mobilities of the grommets is computed according to [26], where the elasticity modulus is estimated from a semi-empirical relation using the shore type (A) hardness [21]. The grommet hardness is characterized for two types of grommets (the joint with the compressor and the joint with fans), twelve specimens of each type of grommet are randomly chosen for testing using a durometer with a type A indentor. Ten data points were measured per specimen and averaged between specimens. From the test data, an average hardness of 35 shore $\mathrm{A}$ is obtained for the grommets in the fan joints and 41 shore $\mathrm{A}$ for the grommets in the compressor joint.

A very important transmission path in the model is the direct sound transmission from the bottom cavity to the reverberation room. It is done through several mechanisms illustrated in Fig. 2(b). First, through the rear plate (subsystem number 18). This transmission path is indicated as 'Plate Grating'. Second, the direct sound 
a)

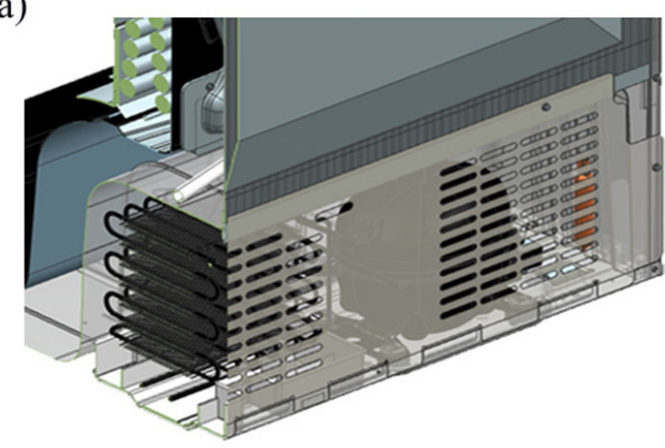

b)

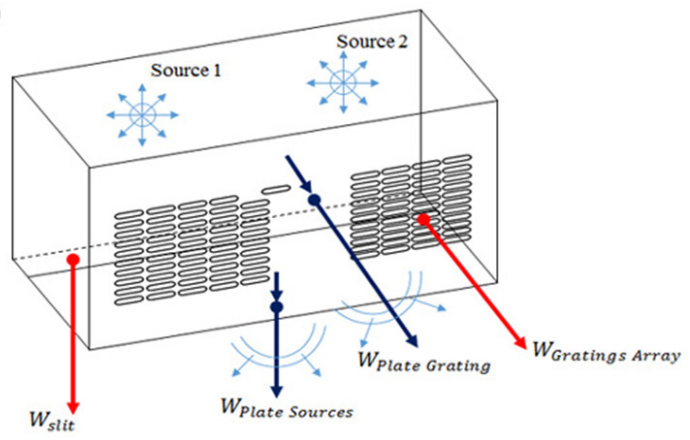

c)

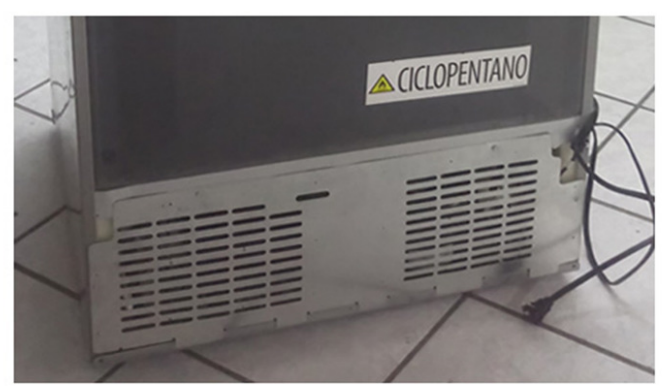

Figure 2: Detailed SEA sketch of the subsystems related with the compressor cavity: (a) 3D render of the grating with translucent plates that allow to see the sources inside as well as the lower opening; (b) Sketch of the subsystems connecting the compressor cavity with the reverberation room through the grating; (c) photo of the grating.

a)

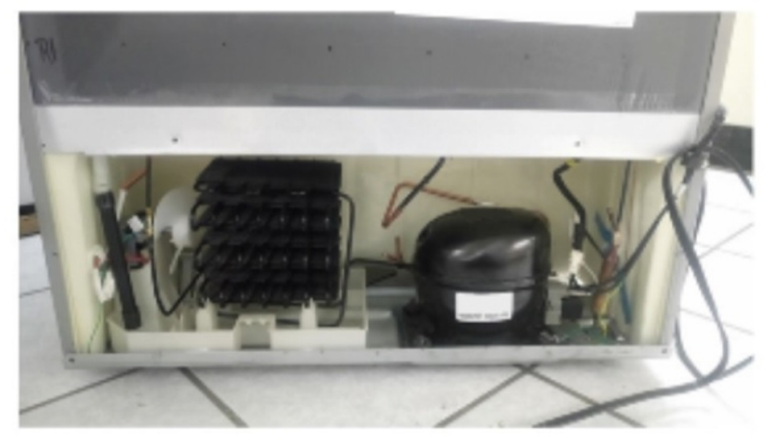

b)

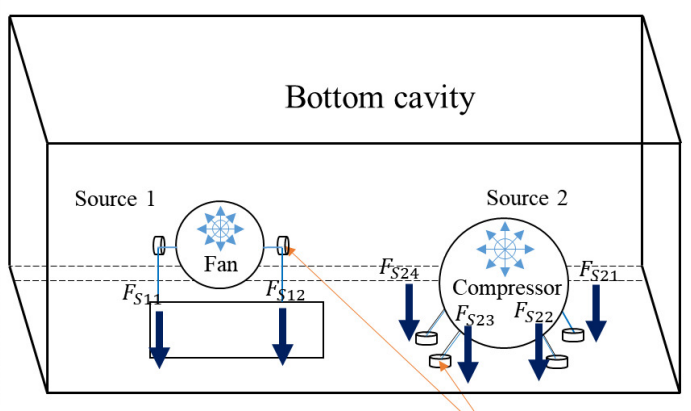

Grommets

Figure 3: Detailed SEA sketch of the subsystems related with the compressor cavity: (a) Photo of the cavity with the compressor; (b) Sketch of the excitations in the compressor cavity.

transmission through the base plate (subsystem number 17). This plate does not cover the whole base of the bottom cavity. The CLF for these transmission paths is 
computed by means of the forced and reverberant sound transmission losses described in [12].

The third mechanism is, the sound transmission through the slit that exists between the base plate and the main fridge structure. This is indicated as 'slit'. The CLF is computed with the formula proposed in [30] and considering a unit acoustic impedance $Z=1$.

$$
\eta_{12}=\frac{c_{0} S_{c} \tau_{12}}{8 \pi f V_{\text {cav } 1}}
$$

where $\tau_{12}$ is the sound transmission coefficient, $S_{c}$ is the area of the linking surface between cavities, $V_{\text {cav } 1}$ is the volume of the bottom cavity.

Finally a fourth transmission mechanism exists. It is the sound transmission through the gratings array, indicated with 'Gratings array'. The CLF is computed by considering the transmission loss provided by the Gomperts' model of slit-shaped apertures, is given by [16]

$$
\tau=\frac{m k \beta}{2 n^{2} \sin ^{2} k \beta\left(\frac{l}{\beta}+2 e\right)+2 k^{2} \beta^{2}}
$$

where $m$ is dependent in the nature of the incident sound field and $n$ on the position of the aperture, $k$ is the wave number, $\beta$ is the width of the slit, $l$ is the depth of aperture and $e$ is the end correction factor for the slit-shaped aperture. The formulation for a single slit is extended to the modelling of grating arrays, by assuming that the contribution of each aperture is independent of the others (they behave as if they were alone). The total sound transmission is computed as the combination of 94 rectangular openings which are $8 \mathrm{~mm}$ in width and $0.457 \mathrm{~mm}$ thick. This hypothesis is sustained in the results presented in $[33,11]$.

In order to provide acoustical transmission between the refrigerator interior cavities, these are connected through the acoustic junctions [12]. The freezer cavity (zone of air discharge by the evaporator fan) is linked to the evaporator cavity (zone of air suction of the evaporator fan) and the food cavity by means of a single opening. On the contrary, the evaporator cavity is linked to the food cavity by means of two openings. These CLFs are computed using Eq. (4).

\subsection{Characterisation of three-layer plates}

The three-layer plate subsystems must be characterised from two points of view. On the one hand their vibration response, assuming that they behave elastically. The homogenised values of elasticity constants and a global value of damping are required. On the other hand, the acoustic absorption that they provide as walls of the internal cavities. Both aspects are discussed here.

The three-layer plates are considered as two rigid plates with damping layer core. The formulation proposed in [25] is used.

If it is assumed that the damping in the internal core layer is much larger than in the top and bottom plates, and that the stiffness in the plates is larger than in the core layer, at high-frequency the damping coefficient can be computed as 


$$
\eta^{H F} \simeq \frac{\eta_{2} G_{2 r} h_{31}^{2}}{2 \pi f h_{2} \sqrt{M^{\prime \prime} B_{r}}}
$$

where $\eta_{2}$ is the damping loss factor of the core layer, $G_{2 r}$ is the real part of the shear modulus of the core layer, $h_{2}$ is the width of the core layer, $h_{31}$ is the distance between the mid-planes of the top and bottom plates and $M^{\prime \prime}$ is the mass per unit area of the composite.

The sound absorption coefficient of the three-layer plates is measured by means of an impedance tube (B\&K Type 4206) with two microphones (B\&K Type 4187) [38]. The measurement is carried out in third-octave frequency bands in the range from $160 \mathrm{~Hz}$ to $6.3 \mathrm{kHz}$. Two sample types with different diameter are considered: for the low frequencies, the diameter is $100 \mathrm{~mm}$ and for high frequencies the sample diameter is $29 \mathrm{~mm}$. Both samples have a thickness of $69 \mathrm{~mm}$ as shown in Fig. 4 . The experiment was set up according to ASTM E1050 [37].

a)

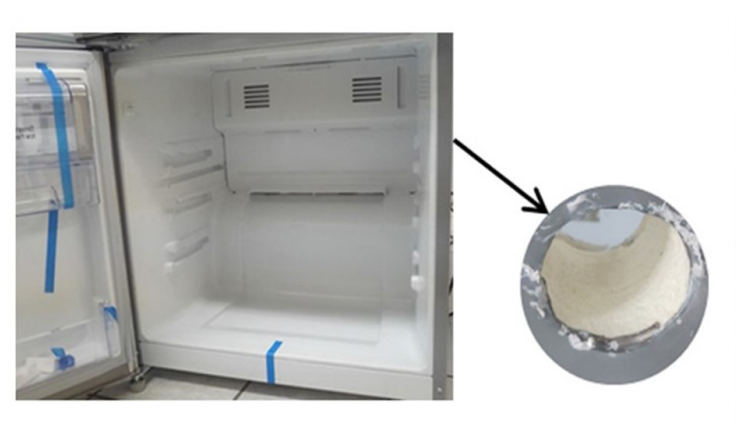

b)

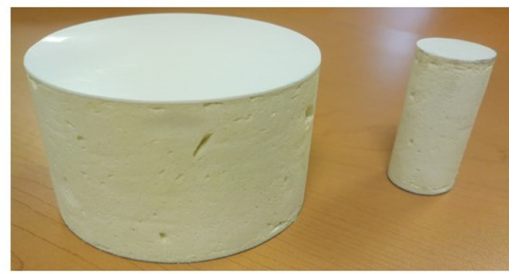

Figure 4: Testing the absorption of the refrigerator shells: (a) Photo of the refrigerator with a hole corresponding to the tested material; (b) material used in the laboratory.

The results are shown in Fig. 5. This data is used to estimate the loss factor of multilayered subsystems [12]. The averaged absorption coefficients $\alpha_{\text {ave }}$ is used to compute the loss factor of the acoustic cavities as

$$
\eta_{i}=\frac{c_{0} A}{8 \pi f V}=\frac{13.7 \sum S \alpha_{\text {ave }}}{f V}
$$

where $c_{0}$ is the speed of sound, $V$ is of volume of the cavity, $A$ is the total absorption in the cavity and $\sum S \alpha_{\text {ave }}$ is the sum of the product of the surface areas and their respective absorption coefficients.

\subsection{SEA model parameters}

In order to develop the model, several SEA parameters are needed. For each structural subsystem, the bending rigidity modulus, damping coefficient and modal density were obtained by means of the equations previously described. The properties of the materials and the dimensions of subsystems given in Table 1.

In Table 1 it is also shown the total bending rigidity modulus for each subsystem. For the three-layer plates, this parameter is obtained using Eq. (1). Using the mechanical and geometric properties shown in the Table 1 for the three-layer plates, the 


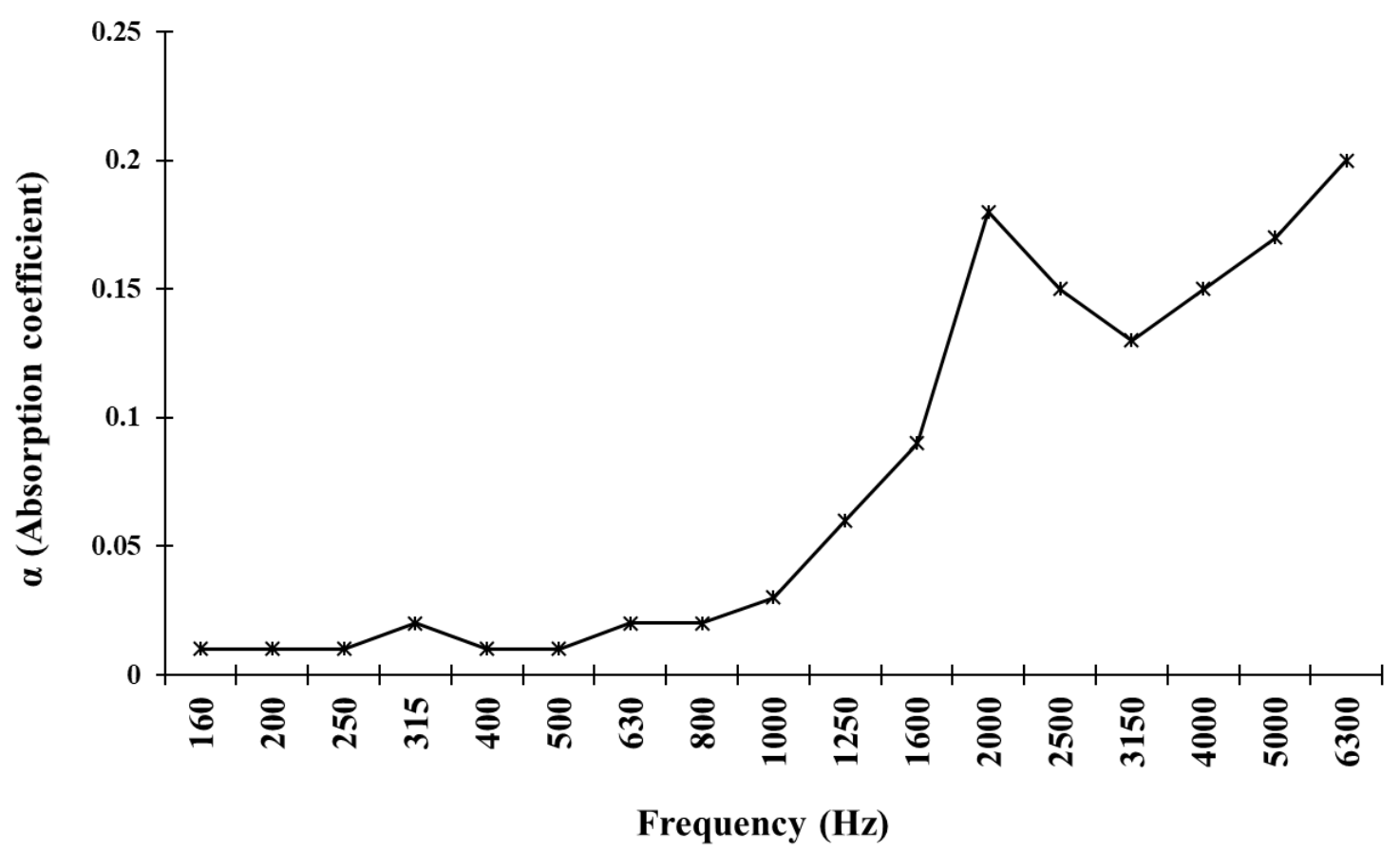

Figure 5: Measured acoustic absorption coefficient for the three-layer material.

equivalent damping coefficient is computed by using Eq. (6). The equivalent damping coefficient calculations are obtained at frequency range from 100 to $10000 \mathrm{~Hz}$ in third-octave bands before plotting the results in Fig. 6 .

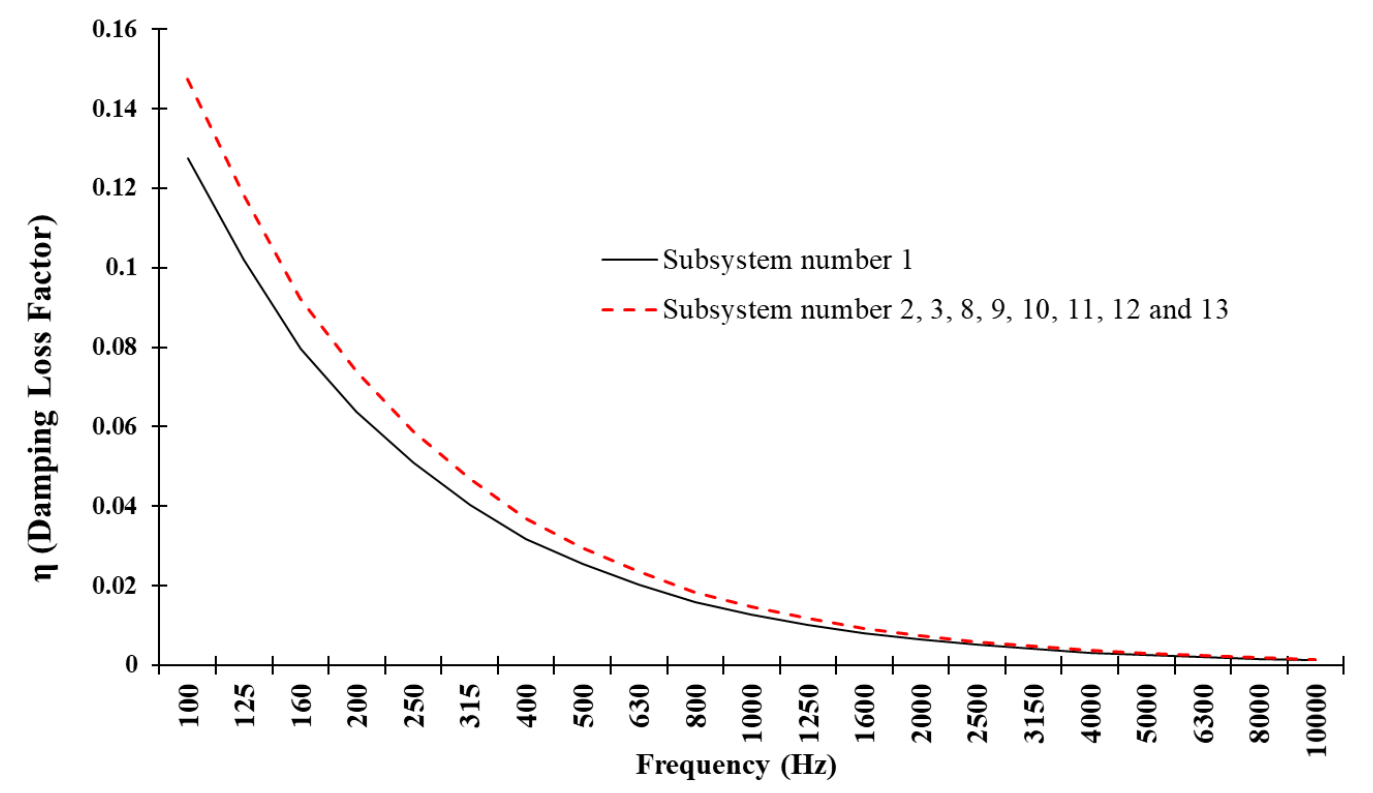

Figure 6: Results for damping loss factor of the three layer plates.

Fig. 6 shows the damping values for plates bending modes, the damping loss factor is the same for the subsystem number $2,3,8,9,10,11,12$ and 13 . This is because the 
Table 1: Material properties of several subsystems used in the SEA model: At the top for homogeneous plates; at the middle, the homogenized properties of the multilayered plates; at the bottom the properties of every layer.

\begin{tabular}{|c|c|c|c|c|c|}
\hline \multicolumn{6}{|c|}{ Single plates } \\
\hline & $\begin{array}{l}\text { Dimensions } \\
m\end{array}$ & $\begin{array}{l}\text { Density } \\
k g / m^{3}\end{array}$ & $\begin{array}{l}\text { Youngs modulus } \\
\qquad N / m^{2}\end{array}$ & $\begin{array}{l}\text { Loss factor } \\
\eta\end{array}$ & $\begin{array}{l}\text { Bending rigidity } \\
\qquad N m\end{array}$ \\
\hline Subsystem number 17 & $0.74 \times 0.2 \times 0.00154$ & 8030 & $1.93 \times 10^{11}$ & 0.005 & 64.1 \\
\hline Subsystem number 18 & $0.74 \times 0.28 \times 4.57^{-4}$ & 8030 & $1.93 \times 10^{11}$ & 0.005 & 1.67 \\
\hline Subsystem number 19 & $0.6 \times 0.37 \times 0.0015$ & 1037.5 & $2520 \times 10^{6}$ & 0.01 & 0.82 \\
\hline \multicolumn{6}{|c|}{ Multi-layered plates } \\
\hline Equivalent properties & $\begin{array}{l}\text { Dimensions } \\
m\end{array}$ & \multicolumn{3}{|c|}{$\begin{array}{ccc}\text { Density } & \text { Youngs modulus } & \text { Total bending rigidity } \\
\mathrm{kg} / \mathrm{m}^{3} & \mathrm{~N} / \mathrm{m}^{2} & \mathrm{Nm}\end{array}$} & \\
\hline Subsystem number 1 & $0.74 \times 0.62 \times 0.0579$ & 116.44 & $1.14 \times 10^{5}$ & 2 & \\
\hline Subsystem number 2 and 3 & $0.99 \times 0.62 \times 0.0679$ & 104.30 & $7.09 \times 10^{4}$ & 2 & \\
\hline Subsystem number 8 and 9 & $0.26 \times 0.4 \times 0.0679$ & 104.30 & $7.09 \times 10^{4}$ & 2 & \\
\hline Subsystem number 10 and 11 & $0.26 \times 0.2 \times 0.0679$ & 104.30 & $7.09 \times 10^{4}$ & 2 & \\
\hline \multirow[t]{6}{*}{ Subsystem number 12 and 13} & $0.61 \times 0.41 \times 0.0679$ & 104.30 & $7.09 \times 10^{4}$ & 2 & \\
\hline & \multicolumn{3}{|c|}{ Layers (Multi-layered plates) } & & \\
\hline & & $\begin{array}{l}\text { Density } \\
\mathrm{kg} / \mathrm{m}^{3}\end{array}$ & $\begin{array}{l}\text { Youngs modulus } \\
\qquad N / m^{2}\end{array}$ & $\begin{array}{l}\text { Loss factor } \\
\eta\end{array}$ & \\
\hline & Layer 1 (HIPS) & 1037.5 & $2520 \times 10^{6}$ & 0.01 & \\
\hline & Layer 2 (Foam) & 34 & $6.7 \times 10^{6}$ & 0.064 & \\
\hline & Layer 3 (Steel) & 8030 & $1.93 \times 10^{11}$ & 0.005 & \\
\hline
\end{tabular}

plates have the same thickness. Also due to the difference in thickness the damping of subsystem number 1 is lower than the other subsystems.

The properties of the acoustic SEA subsystems are summarised in Table 2. Uniform absorption all around the cavity surfaces is assumed.

Table 2: Properties of cavity subsystems used in the SEA model.

\begin{tabular}{llcc|cccccc}
\hline$\#$ & Subs. & Volume & Total area & \multicolumn{5}{c|}{ Absorption $(\alpha)$ at the $f(\mathrm{~Hz})$} \\
& descr. & $m^{3}$ & $m^{2}$ & 125 & 250 & 500 & 1000 & 2000 & 4000 \\
\hline 22 & food & 0.310 & 2.818 & 0.01 & 0.01 & 0.01 & 0.03 & 0.18 & 0.15 \\
23 & freezer & 0.182 & 1.927 & 0.01 & 0.01 & 0.01 & 0.03 & 0.18 & 0.15 \\
24 & bottom & 0.0326 & 0.674 & 0.01 & 0.01 & 0.01 & 0.03 & 0.18 & 0.15 \\
25 & evapor. & 0.0365 & 0.711 & 0.01 & 0.01 & 0.01 & 0.03 & 0.18 & 0.15 \\
26 & reverb. & 289.79 & 263.5 & 0.06 & 0.05 & 0.07 & 0.15 & 0.13 & 0.17 \\
\hline
\end{tabular}

\section{Results}

\subsection{Laboratory measurements: Refrigerator noise in the re- verberant field}

A test on a reverberation room was used to validate the SEA model. The measured output is the noise generated by a full refrigerator in a diffuse field, this is done ac- 
cording to the regulation ISO-3741 [4] by the comparison method using a reference sound source (B\&K type 4204). The refrigerator is placed following the IRAM-2404 standard [3], located at one meter from the chamber wall in the middle of the reverberation room as shown in Fig. 7. The tests were carried out in two configurations: with the refrigerator working on full mode (with all the sources active at the same time) and with only one source active (compressor, evaporator fan or condenser fan).

The SPL measurement is performed using a boom with an arm of $3.2 \mathrm{~m}$ in length with microphone (B\&K Type 4942-L) and processed with a data acquisition system (B\&K Type 3160-A-022) as shown in Fig. 7. It is also verified that the noise generated by the refrigerator is larger than the background noise in the chamber. The noise level with the diffuser and boom rotating but the refrigerator off is always $20 \mathrm{~dB}$ - $24 \mathrm{~dB}$ smaller. The measurements were collected on a range from 100 to 10000 $\mathrm{Hz}$ and processed into one third-octave frequency bands with a time averaging of 32 seconds. The sound pressure levels at one meter with A-weighting is then computed as described in ISO-3741 regulation.

a)

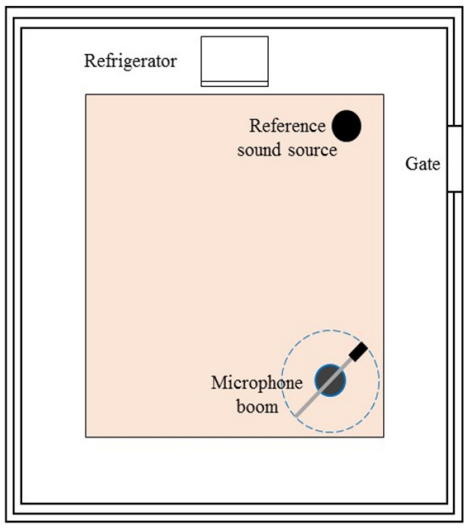

b)

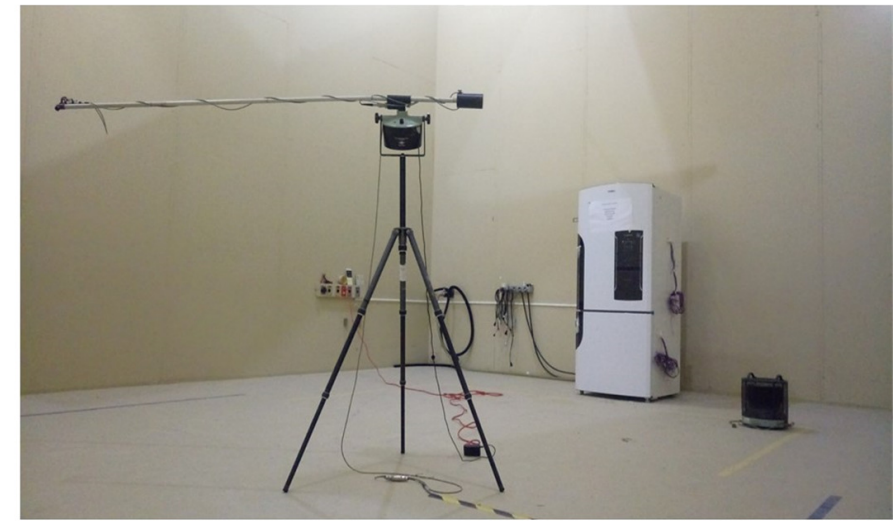

Figure 7: Sketch of the measurement of acoustic pressure generated by the refrigerator according to the IRAM-2404 standard [3]:(a) Top view of the reverberation room; (b) Photo of the test: rotary microphone and setup for measurement the sound pressure level generated by a refrigerator into reverberation room according to the ISO-3741 [4].

The measured SPL of the refrigerator working on full mode and working on a single source is shown in Fig. 8. In all cases, the frequency bands that contribute more to the global noise are those between: $250 \mathrm{~Hz}$ and $1250 \mathrm{~Hz}$. In general, the SPL decreases at high frequencies while it has peaks at low and mid frequencies.

\subsection{Comparison of the SEA model with the measurements}

The experiment described in Sect. 3.1 is compared with a SEA simulation of the refrigerator. This is important in order to check if the parameters required for the complete SEA model are properly determined: transmission loss factors, coupling loss factors, internal loss factors (sound absorption coefficient and damping of the three-layer plates) and power inputs by sources. 


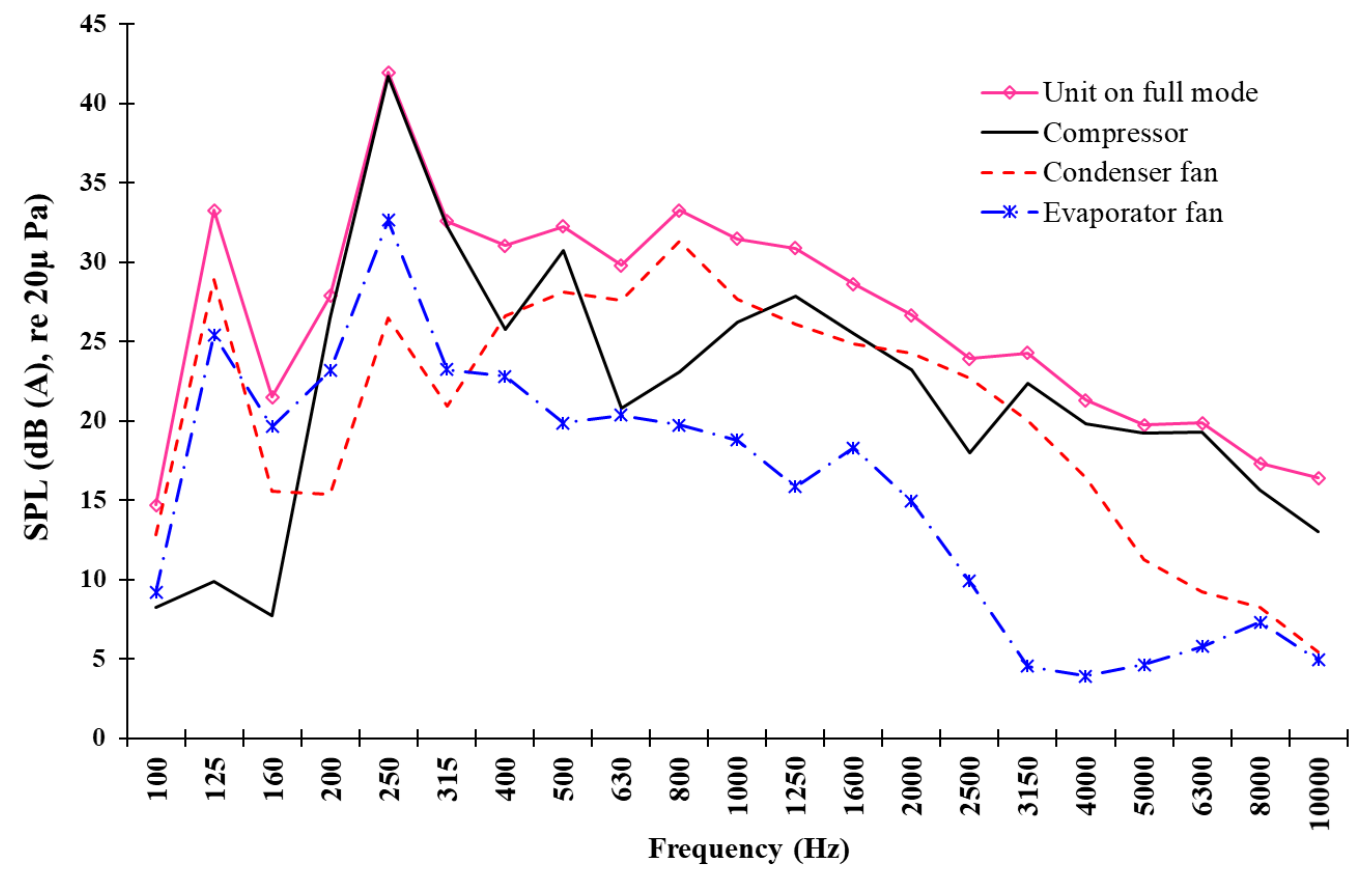

Figure 8: Frequency band spectrum of refrigerator measurements: Full refrigerator (overall SPL of $44.9 \mathrm{~dB}(\mathrm{~A})$ ), compressor only (overall SPL of $43.2 \mathrm{~dB}(\mathrm{~A})$ ), evaporator fan only (overall SPL of $35.3 \mathrm{~dB}(\mathrm{~A})$ ) and condenser only (overall SPL of $38.0 \mathrm{~dB}(\mathrm{~A})$ ).

The SEA model is used to estimate the sound pressure level generated by a commercial refrigerator in a reverberant field. Fig. 9 shows the simulation estimation and experimental measurements of the refrigerator working in full mode. There is a good agreement between prediction and experimental data. The prediction presents a maximum difference with respect to experimental data in the sound pressure level curve of $2.23 \mathrm{~dB}(\mathrm{~A})$. The larger differences are found between $630 \mathrm{~Hz}$ and $1250 \mathrm{~Hz}$, and at $10000 \mathrm{~Hz}$. However, they are within acceptable limits, taking into account the complexity of the modelled vibroacoustic system.

Fig. 10(a) shows the simulation estimation and experimental measurements of the refrigerator working on the compressor only mode. There is a good agreement from 250 to $10000 \mathrm{~Hz}$ with a minimum and maximum difference of 0.02 and $2 \mathrm{~dB}(\mathrm{~A})$ respectively. Results at low frequency bands from 125 to $200 \mathrm{~Hz}$ have a minimum and maximum difference of 2.6 and $8.2 \mathrm{~dB}(\mathrm{~A})$ respectively, affected by low mode count of some subsystems.

The results for the refrigerator working on the condenser fan only mode are shown on Fig. 10(b). There is also a good agreement from 250 to $4000 \mathrm{~Hz}$ with a minimum and maximum difference of 0.02 and $1.8 \mathrm{~dB}(\mathrm{~A})$ respectively. Results at low frequency bands of 160 and $200 \mathrm{~Hz}$ display a minimum and maximum difference of 1.9 and $3.6 \mathrm{~dB}(\mathrm{~A})$ respectively, also affected by low mode count of some subsystems. High frequency bands of 5000 to $10000 \mathrm{~Hz}$ have a minimum and maximum difference of 1.82 and $4.41 \mathrm{~dB}(\mathrm{~A})$ respectively, affected by the transmission paths from the compressor cavity to the reverberation room through the ventilation grating.

Fig. 10(c) shows the comparison between predictions and measurements when the 


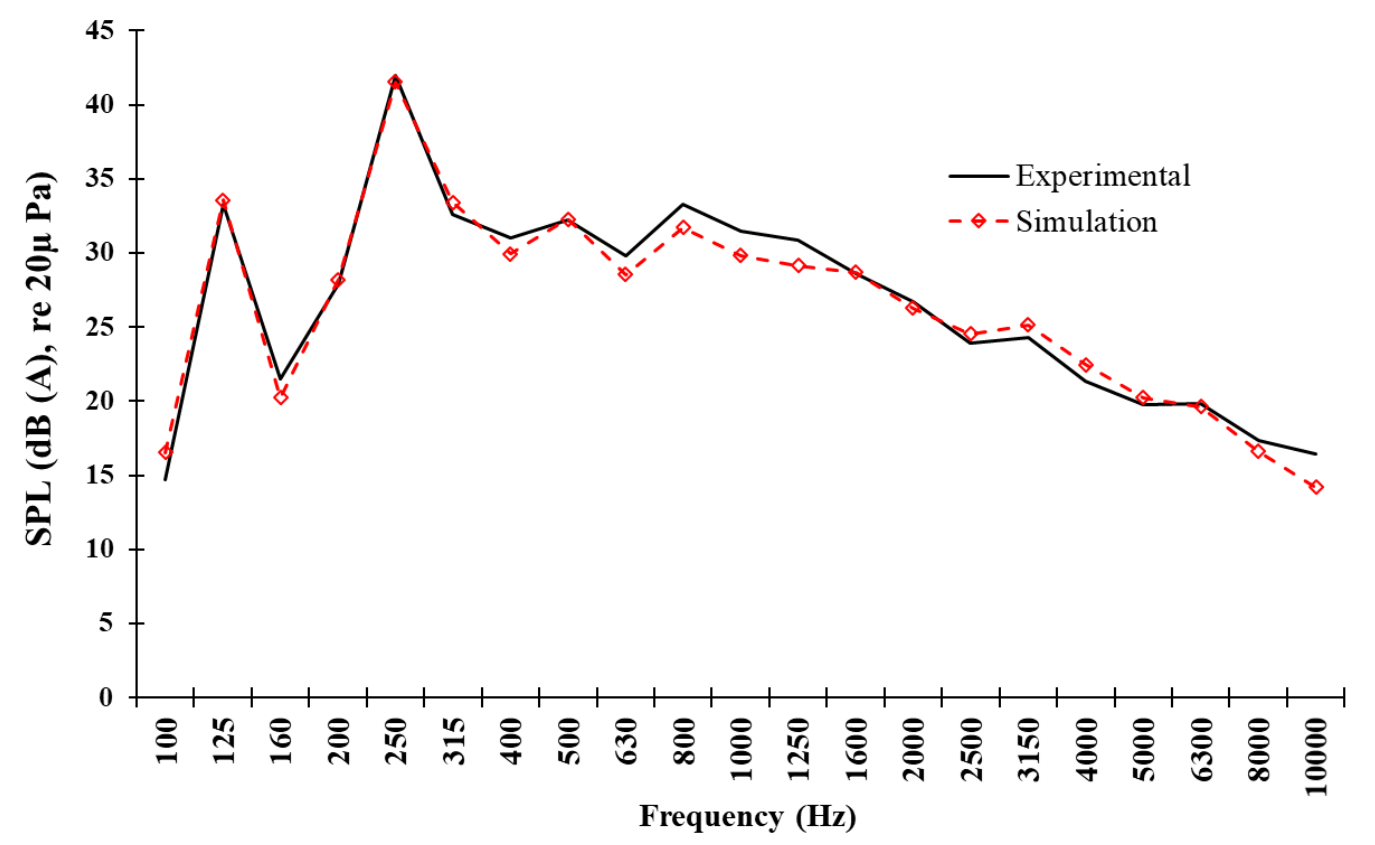

Figure 9: Comparison between predicted SPL and measured data.
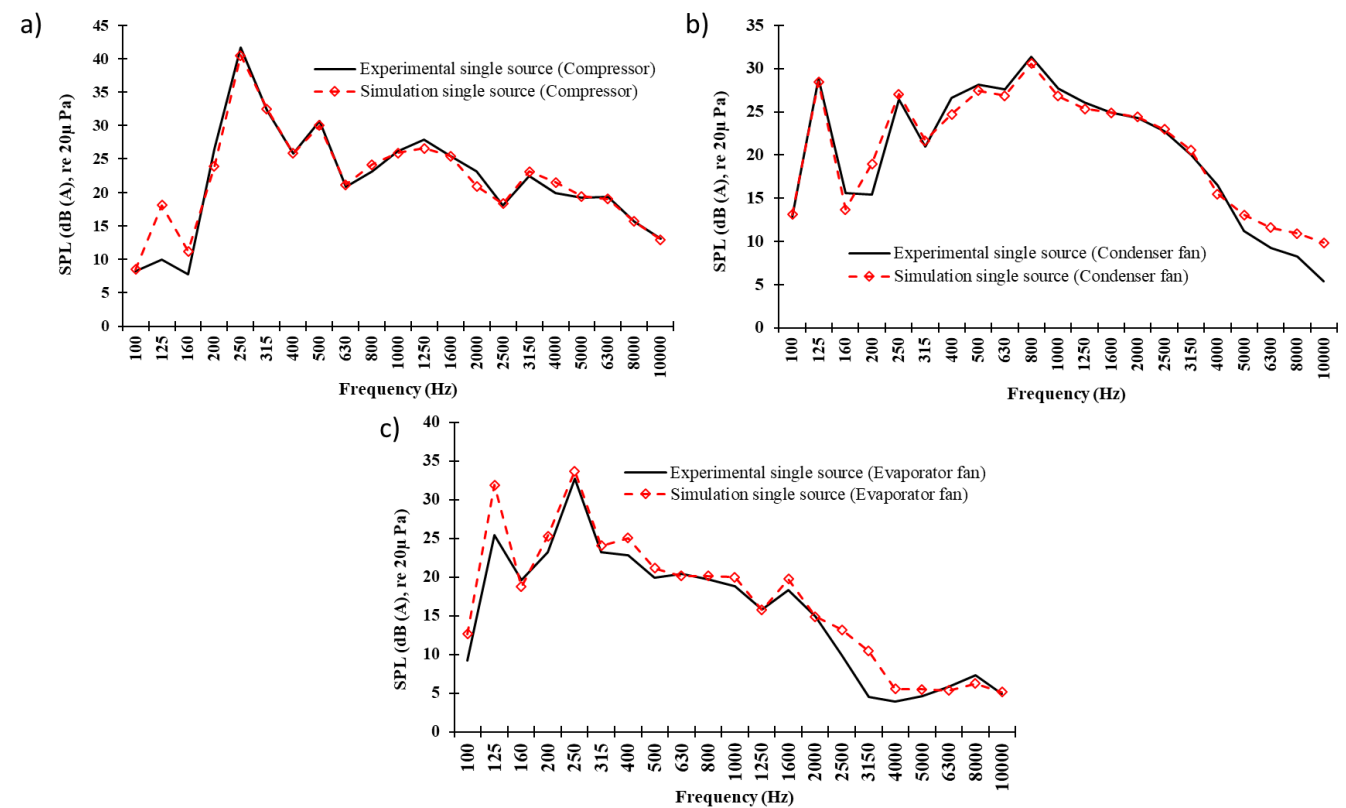

Figure 10: Source only comparison between predicted and measured SPL: (a) Compressor; (b) Condenser fan; (c) Evaporation fan.

refrigerator works only with the evaporator fan. The agreement is good from 160 to $315 \mathrm{~Hz}, 500$ to $2000 \mathrm{~Hz}$ and 4000 to $10000 \mathrm{~Hz}$, with a minimum and maximum difference of 0.09 and $2 \mathrm{~dB}(\mathrm{~A})$ respectively. Results at low and middle frequency bands, from 100 to $125 \mathrm{~Hz}$ and $400 \mathrm{~Hz}$, show a minimum and maximum difference of 2.2 and $6.4 \mathrm{~dB}(\mathrm{~A})$, affected by the low mode count of some subsystems. High 
frequency bands of 2500 to $3150 \mathrm{~Hz}$ have a minimum and maximum difference of 3.3 and $5.9 \mathrm{~dB}(\mathrm{~A})$ respectively, affected by the sound insulation provided by the multilayered plates that conform the freezer cavity.

\subsubsection{Hypotheses verification of the SEA model}

The validity of the SEA model in terms of hypotheses fulfillment has been corroborated by means of the criteria defined in [23]. A set of parameters concerning the physical properties of subsystems and the coupling between then need to be computed. If their values satisfy the criteria, it can be ensured that the SEA model satisfy the SEA hypotheses. This verification tend to be on the safe side.

The subsystems with smaller modal densities are the cavities 24 (bottom) and 25 (evaporator). They do not have a reasonable number of modes (at least $N>10$ ) in each third-octave band below $1000 \mathrm{~Hz}$. The other two problematic subsystems in terms of the modal densities are the cavities 22 (food) and 23 (freezer), but they fix the lower valid frequency at $500 \mathrm{~Hz}$ (less restrictive). All the other subsystems have enough modes above $250 \mathrm{~Hz}$.

The diffuse field hypothesis (normalised attenuation factor $\bar{m}<1$, attenuation factor of wave per length times the mean free path) is a less restrictive hypothesis for the studied problem. It is satisfied for all the subsystems in the frequency range of interest.

Some subsystems suffer from a poor modal equipartition at some low frequencies (we consider that it must be $M>1$ ). This is the case of the subsystem 17 (inferior plate), for which the frequency should be higher than $1000 \mathrm{~Hz}$ in order to reach the modal overlap $M>1$. Also the cavities 24 and 25 require the frequency to be higher than $500 \mathrm{~Hz}$.

Almost all the couplings involved in the model are weak $\left(\eta_{i j} / \eta_{i i}<1\right)$. However, there are four connections for which the coupling can be strong. The most critical is the connection between the bottom cavity and the reverberation room, showing a strong coupling due to the multiple transmission paths. The reverberation room is also strongly coupled with the evaporator and the food cavity at frequencies below 500

$\mathrm{Hz}$. Finally, the coupling of the reverberation room and the bottom plate (subsystem 17) can also be strong at the critical frequency of the plate.

To sum up, we can establish $1000 \mathrm{~Hz}$ as the frequency for which all the indicators proposed in [23], except the weak coupling between the reverberation room and the bottom cavity, are satisfied. The mentioned coupling is not weak in all the cases analysed. However, it is quite commonly accepted that the existence of some strong couplings does not invalidate a SEA model.

To sum up, we can establish $1000 \mathrm{~Hz}$ as the frequency for which all the indicators proposed in [23] are satisfied. With exception of the weak coupling between the reverberation room and the bottom cavity, that is never satisfied. It is however quite commonly accepted that the existence of some strong couplings does not invalidate a SEA model.

In the validation examples where the SEA predictions are compared with the laboratory measurements, the agreement of the outputs is good even at low frequencies around 100 or $200 \mathrm{~Hz}$. This contradicts with the fact that the SEA hypotheses 
are not fully satisfied in this frequency range. A reason that can explain this good agreement is that the power radiated to the reverberation room is highly dependent on the connection between the bottom cavity and the reverberation room. So, if the transmission mechanisms between these two subsystems are properly described, the results can be good also at low frequencies, because this is a dominant path.

\subsection{Simulating the fridge response by means of the SEA model}

\subsubsection{Dominant transmission paths}

The good agreement shown on the comparison between the experimental measurements and the results predicted by the SEA model means that this simulation tool is good enough for: i) gaining knowledge on the vibroacoustic behavior of the refrigerator; ii) visualizing information which is difficult to measure in the experiments; iii) making some modifications in the model to avoid the realization of new experiments on modified prototypes of the refrigerator.

The first aspects to be studied are the main paths through which the acoustic power is transmitted from the refrigerator to the chamber. The energy flow between subsystems is a non straightforward measurable output in the experiments. However, it provides very useful information in order to improve the vibroacoustic design. Only the paths with major exchange of power flow are plotted in Fig. 11, while the less meaningful paths are not plotted.

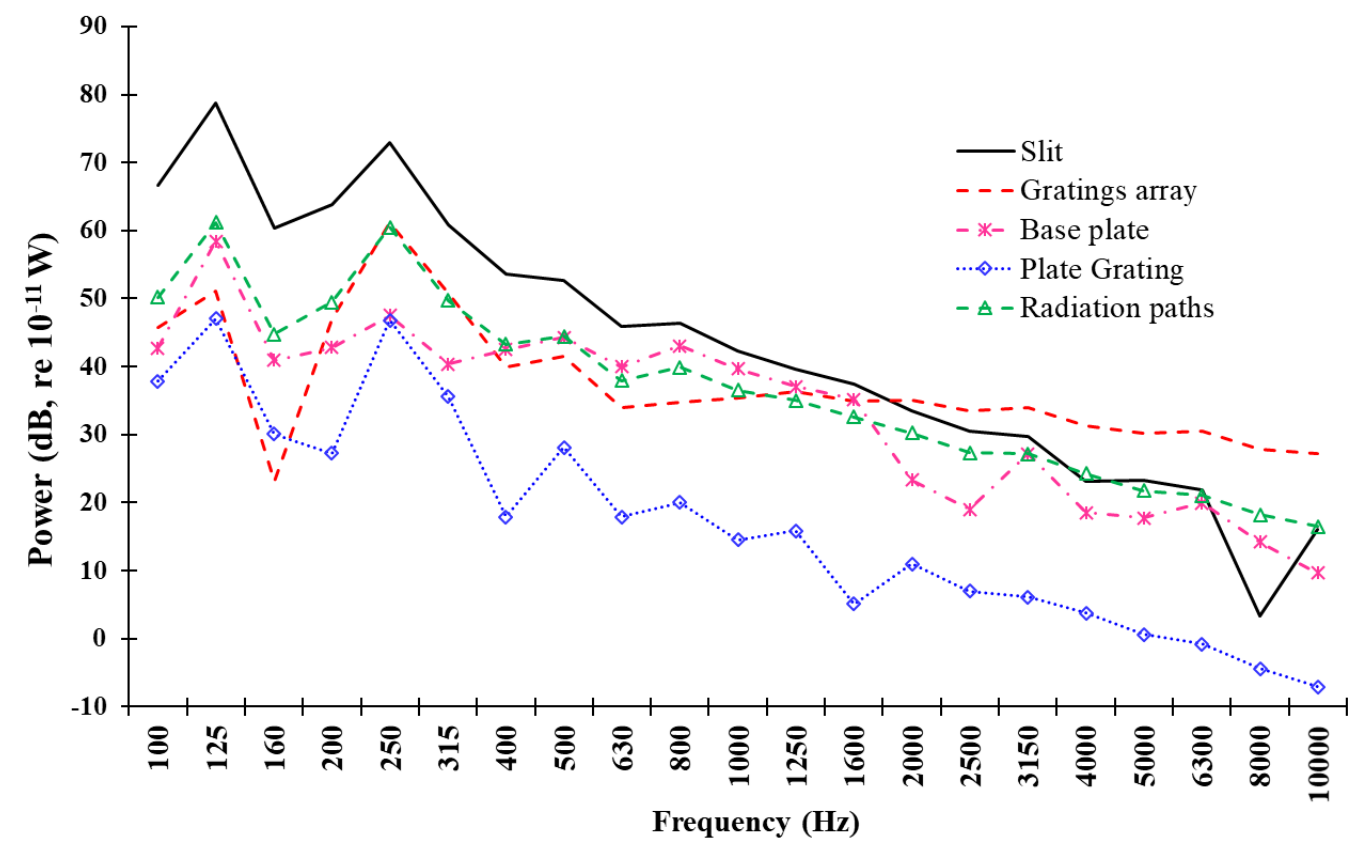

Figure 11: Estimation of main power flows of refrigerator to chamber.

Fig. 11 shows that the path with a maximum power flow at the frequency range from 100 to $1600 \mathrm{~Hz}$ is the slit path, and for frequencies above $1600 \mathrm{~Hz}$ the path 
with maximum power flow is the gratings array. Other paths that also provide an important amount of power flow are the 'base plate' and the 'plate grating'. Finally, a path called 'radiation paths' is plotted, which is the sum of all the power of the paths going from the refrigerator outer casing to the reverberation room. This represents the addition of the power radiated by the subsystems $1,2,3,4,7,8,9,10,11,12,13$, $14,20,21,22,23,25$ to the reverberation room.

In this comparison between the paths that represent direct power transmission from the compressor cavity to the reverberation room (through the different transmission mechanisms) with the power radiated due to the vibration of the refrigerator outer casing (due to the numerous paths of power transmission through the structure), it can be concluded that most of the noise generated into the reverberation room comes from the compressor cavity.

\subsubsection{Global noise sensitivity to direct sound transmission paths (slit and gratings array)}

Based on the model predictions, the slit and gratings array are identified as the most contributing sound transmission paths, so their sensitivity and effect on the refrigerator global noise is quantified.

These transmission mechanisms depend on an adequate estimation of the transmission loss using several wave models. For the prediction shown above, the transmission loss for the gratings array is based on the model provided by Gomperts [16] for holes, while the slit is considered with a unit acoustic impedance $Z=1$. To check the global noise sensitivity by the estimation of this parameter, three different simulations were carried out. First, only using the Gomperts model of the slit-shaped apertures for the two transmission mechanisms. Second, using the Gomperts model of slit-shaped apertures for the slit transmission mechanism and Gomperts model of circular-shaped apertures for the gratings array transmission mechanism. Finally, a unit acoustic impedance $Z=1$ was considered for the two transmission mechanisms.

Fig. 12 shows the results obtained with the three different models and the experimental measurements. There is a good agreement between the three different predictions and experimental data. The three simulations present the same behavior on the frequency range from 100 to $1600 \mathrm{~Hz}$. The prediction using only Gomperts model by slit-shaped apertures presents an overall noise difference with respect to experimental data of $0.43 \mathrm{~dB}(\mathrm{~A})$; the prediction using Gomperts model by slit and circular-shaped apertures presents an overall difference of $0.69 \mathrm{~dB}(\mathrm{~A})$; and the prediction using only acoustic impedance $Z=1$ presents an overall difference of 0.51 $\mathrm{dB}(\mathrm{A})$.

The difference in terms of global noise between the modeling an acoustic impedance $Z=1$ and the models that use a more detailed description of the slit and gratings array are not very large, $0.5 \mathrm{~dB}(\mathrm{~A})$ on overall noise. This could mean that the influence of the perforated plate (with grating array) is not very important. To validate this hypothesis, SPL measurements using the setup described in Sect. 3.1 and sound intensity measurements using the setup described in the standard ISO-9614 [6] in a semi-anechoic chamber for the two situations, with and without plate, were performed and compared. The intensity measurements are done by means of a 98 nodes mesh 


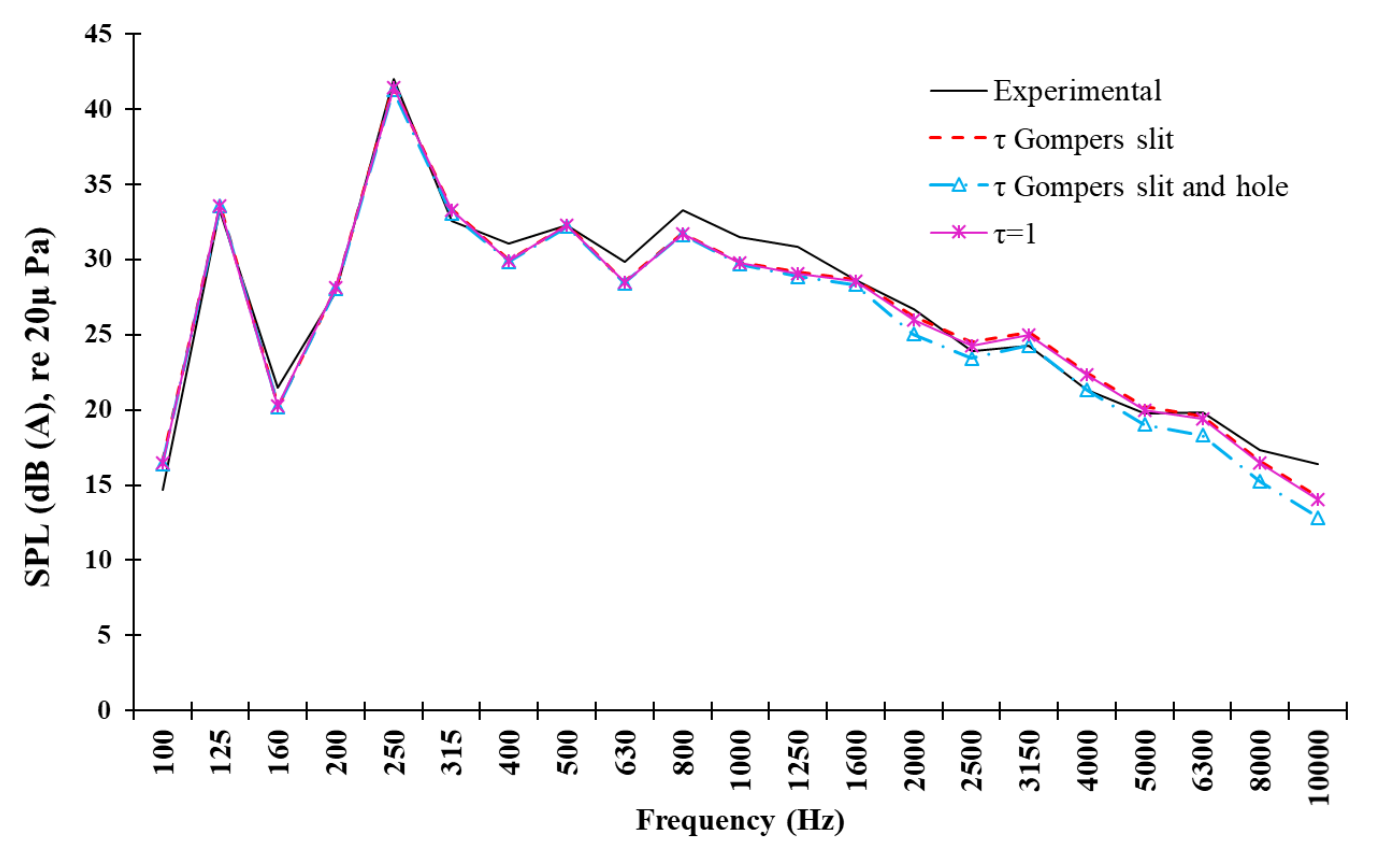

Figure 12: Comparison between SPL prediction only model Gomperts for slit, model Gomperts for slit and hole, impedance $Z=1$ and experimental results.

with the refrigerator working on full mode. A sound intensity probe (B\&K type 3595 with a pair of microphones B\&K type 4197) which is placed $15 \mathrm{~cm}$ away from each side of the refrigerator is used.

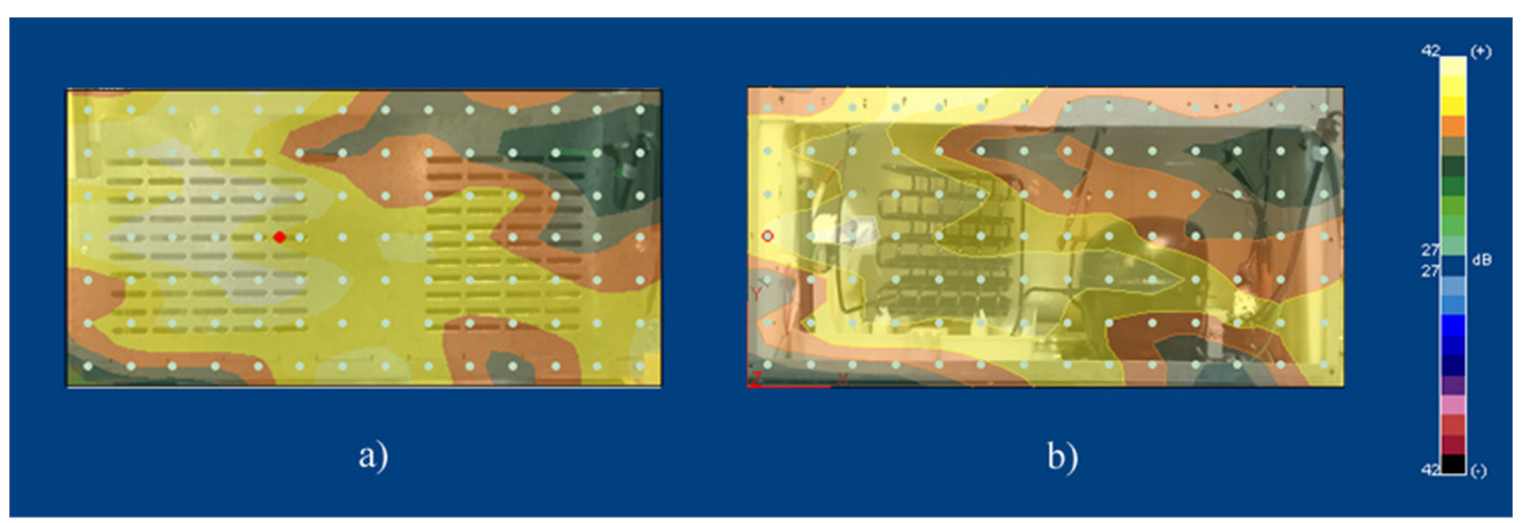

Figure 13: Sound intensity contour map of the lower back part of the refrigerator at $800 \mathrm{~Hz}$; (a) with plate ; (b) without plate (noise can pass directly from the compressor cavity to the reverberation room).

Fig. 13 shows the sound intensity map at $800 \mathrm{~Hz}$. At this frequency there is a peak contribution of the refrigerator to the global noise in the reverberation room. The figure compares two cases: with plate (Fig. 13(a)) and without plate (Fig. 13(b)). The pattern in the intensity contour map is very similar in both cases. This validates the hypothesis on the small influence of the plate on the global acoustic behaviour. 
Another global noise sensitivity factor investigated was the removal of the transmission mechanisms on the SEA model. Three different iterations were considered: first, removing only the gratings array transmission mechanism; second, removing only the slit transmission mechanism; third, removing both transmission mechanisms.

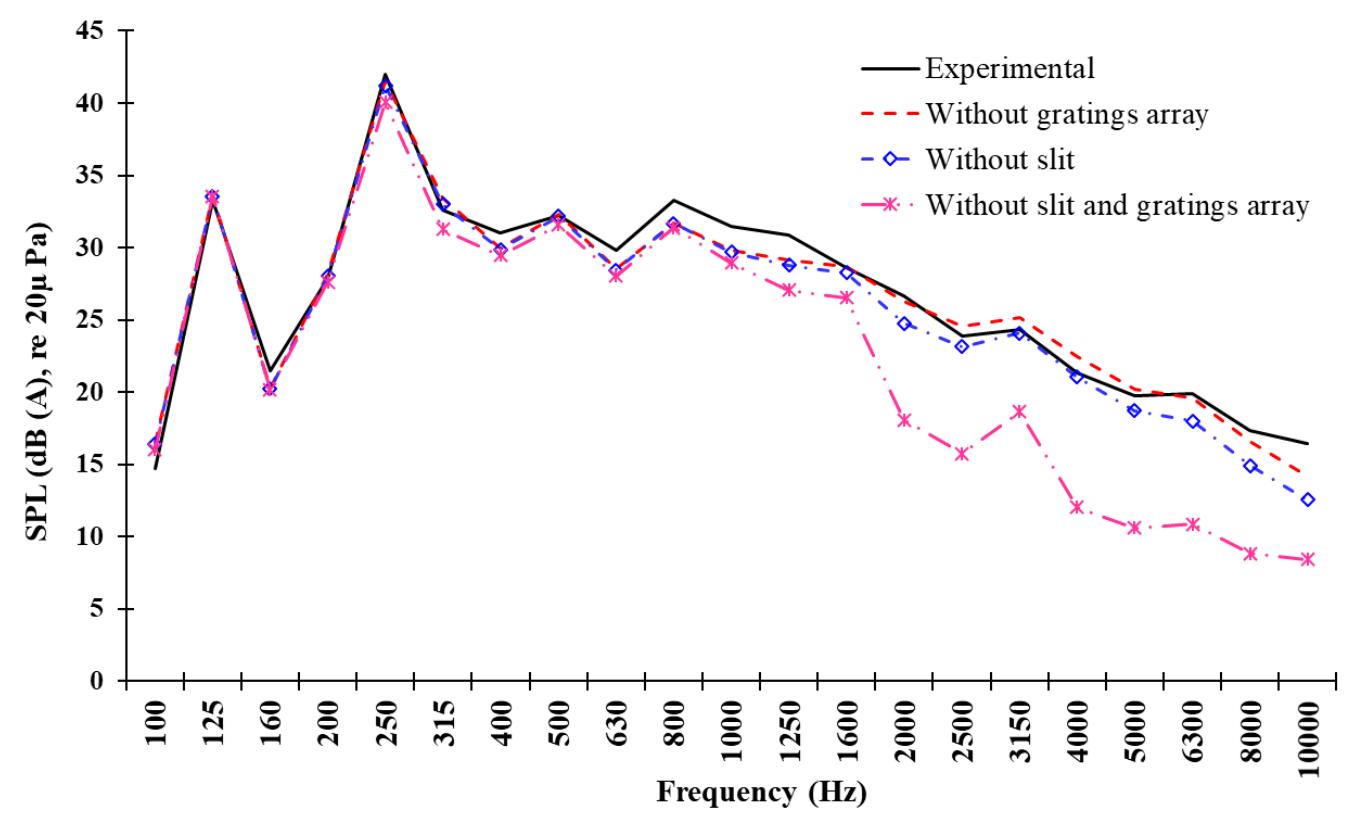

Figure 14: Comparison between SPL prediction without grating, without slit, without grating and slit and experimental results.

The results are shown in Fig. 14. When removing only one of the two transmission mechanisms (curves 'Without gratings array' and 'Without slit') the variation is small. However, when removing both transmission mechanisms at the same time (curve 'Without slit and gratings array') the modification is important in the frequency range between 1600 and $10000 \mathrm{~Hz}$ (overall noise reduction of $2.2 \mathrm{~dB}(\mathrm{~A})$ ). This shows the influence of these transmission mechanisms at high frequencies. At least one of them must be considered in order to properly reproduce the reference curve.

Fig. 15 shows which are the most contributing paths (in terms of power flow through the reverberation room) in the virtual scenarios where the most critical transmission paths are blocked. This provides information on the expected behaviour in the case of implementation of design improvements. The information is helpful in order to take decisions and focus the efforts in the most critical parts of the device.

The new values of the power flow for the remaining paths does not show a very large variation. It could indicate that the suppression of the slit and gratings array path would lead to global improvements. The most important differences are that the vibration paths ('plate gratings' and 'base plate') become more relevant and contribute more to the global noise genrated by the refrigerator, especially at frequencies above $2000 \mathrm{~Hz}$. A possible explanation is that in the new energy distribution, more vibration energy is concentrated on the elements that surround the compressor cavity. 

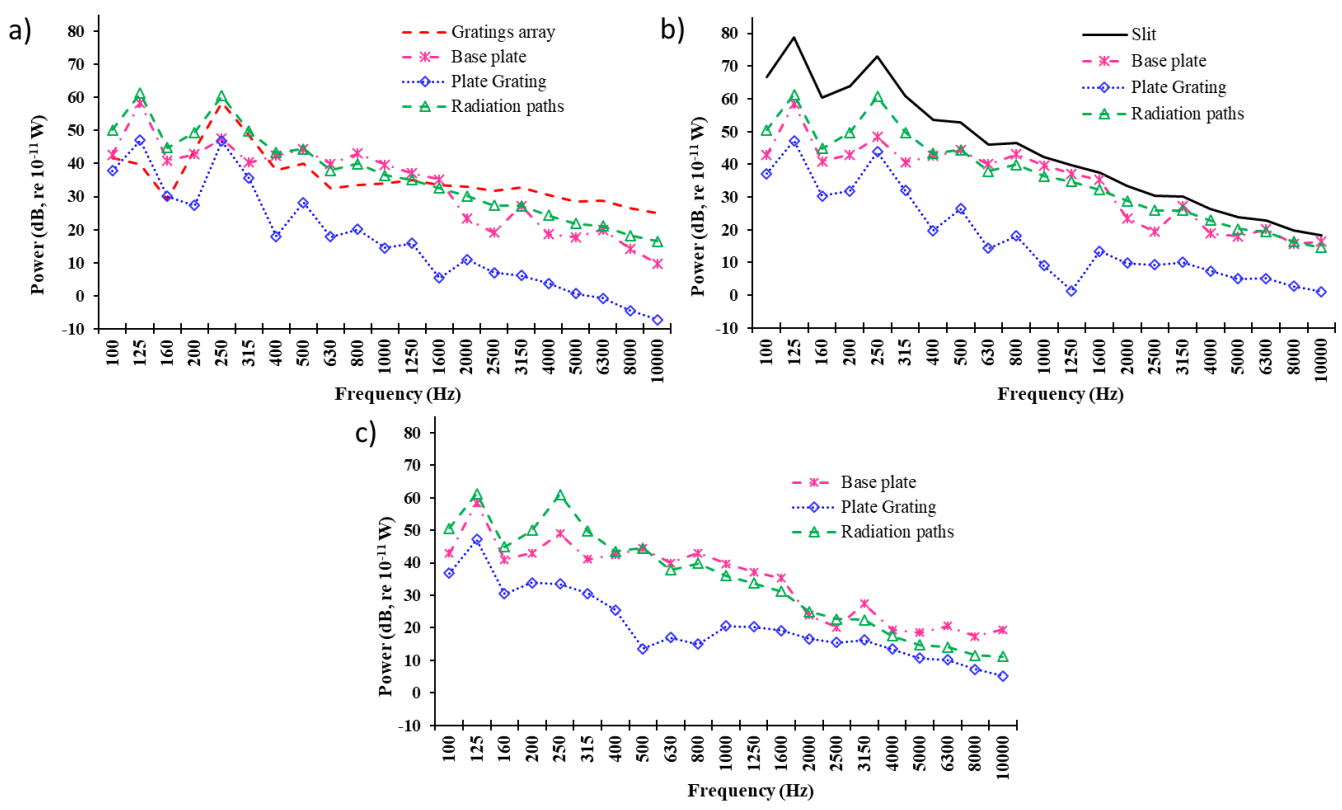

Figure 15: Power flow of the most contributing paths to the SPL of the reverberation room in the scenarios where it is virtually blocked: (a) the transmission through the bottom slit; (b) the transmission through the gratings array; (c) both transmissions in (a) and (b) at the same time.

\subsubsection{Global noise sensitivity to grommets}

The vibration and radiation of the base plate is identified as one of the important contributions of noise in the reverberation room. There are two sources, compressor and fan, directly attached to this base plate. This cause a direct injection of mechanical power to the plate as explained in Sect. 2.1. Grommets are used in order to attenuate the direct transmission of vibrations from the sources to the plate through the supporting structure. Here, their influence is quantified by means of the SEA model.

The results are shown in Fig. 16. The influence of the grommets on the global response is very limited. The maximum increase on SPL when grommets are not used is $1 \mathrm{~dB}(\mathrm{~A})$. This is mainly seen in the frequency range from 630 to $1600 \mathrm{~Hz}$.

\section{Conclusions}

A SEA model of a fridge has been presented and validated. The model is complex due to the large number of subsystems involved and also the different nature of them: plates of different type (homogeneous, layered) and acoustic cavities (inside the fridge and the reverberation chamber where the test is done). Several transmission and radiation mechanisms must be also considered: forced and resonant transmission through the different plate types, transmission through holes, apertures and gratings array, and structural connections (junctions and point / strings). Some elements of the fridge represent a challenge from a modelling point of view due to their complex design. 


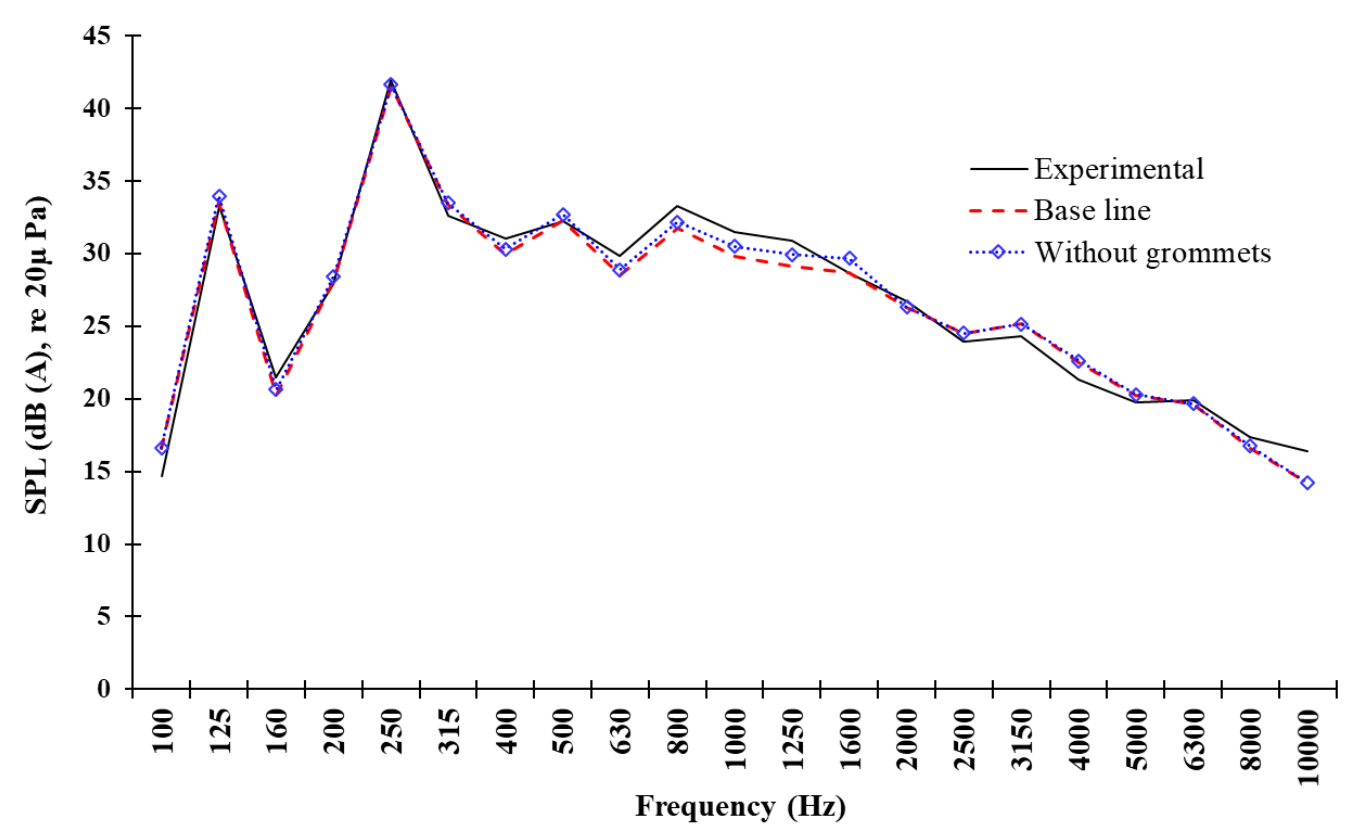

Figure 16: SPL prediction for two different models: with and without grommets. Comparison with experimental results (with grommets).

The acoustic and vibration sources are a good example: compressor and fans. These parts of the model for which simple formulations do not exist, have been characterised by means of experimental data (laboratory experiments of this parts isolated). It is shown how the combination of measured inputs and classical formulas has lead to a good final result.

The main conclusions that can be obtained from the research are as follows:

1. There is a good correlation between the simulation results and the measured data. This is shown, for example in Fig. 9 for the refrigerator in the usual working conditions, and in Fig. 10 for the refrigerator working only with some of the vibroacoustic sources active. The agreement is also good at quite low frequencies where SEA hypotheses tend to be not fully satisfied.

2. In the current configuration of the refrigerator, the most critical paths in terms of noise generated in the room are those related with the compressor cavity, and more precisely the sound transmission through an slit in the base of that cavity. This is the dominant path at almost all the frequencies. The main transmission paths help to identify the most significant parameters and dimensions on the design affecting the vibroacoustic performance of the refrigerator.

3. The order of magnitude of any of the critical paths (all four transmission mechanisms starting at the compressor cavity) is comparable with all the other sound generated by the vibration of the refrigerator structure ('radiation paths').

4. There are not very large differences between most of the refrigerator models. It means that some of the knowledge gained in the presented analysis could be 
used to improve other designs. For example the relative importance of the paths must not be very different between models and it means that a key aspect is the proper design of the compressor cavity. The small influence of the plate that contains an array of gratings in the overall response and acoustic intensity on the back part of the refrigerator is also a generalisable aspect to most of the models. The materials used (such as the three-layer plates) are quite common, which means that some of the provided values of stiffness and damping represent a good reference to have a magnitude order.

\section{Acknowledgements}

The authors would like to thank the support of the Consejo Nacional de Ciencia y Tecnología México (CONACyT-scholarships program) and the Universidad Nacional Autónoma de México, DGAPA-UNAM (proyectos PAPIIT-PAPIME). LaCàN research group is grateful for the sponsorship/funding received from Generalitat de Catalunya (Grant number 2017-SGR-1278). The acoustic laboratory of Mabe for their support and providing the installations to develop the study.

\section{References}

[1] EN 15657-1 acoustic properties of building elements and of buildings laboratory measurement of airborne and structure-borne sound from building equipment, part 1: Simplified cases where the equipment mobilities are much higher than the receiver mobilities, taking whirlpool baths as an example; 2009.

[2] EN 60704:2014 household and similar electrical appliances test code for the determination of airborne acoustical noise.

[3] IRAM. Norma 2404-3. Etiquetado de eficiencia energtica para aparatos de refrigeracin de uso domstico. parte 3- etiqueta. Instituto Argentino de Normalizaciòn y Certificaciòn, 2015.

[4] ISO 3741:2010. Acoustics -determination of sound power levels and sound energy levels of noise sources using sound pressure. International Organization for Standardization, 2010.

[5] ISO 9611:1996. Characterization of sources of structure-borne sound with respect to sound radiation from connected structures measurement of velocity at the contact points of machinery when resiliently mounted. International Organization for Standardization, 1996.

[6] ISO 9614-1:1993. Determination of sound power levels of noise sources using sound intensity. International Organization for Standardization, 1993.

[7] D. Barpanda and J. M. Tudor. Solutions-based approach for reducing noise in washing machines. Sound and Vibration, 19(11):6, 2009. 
[8] G. Borello. Virtual SEA analysis of a warship classification. In 10ème Congrès Français d'Acoustique, 2010.

[9] M. Carfagni and M. Pierini. Determining the loss factor by the power input method (PIM), part 2: experimental investigation with impact hammer excitation. Journal of Vibration and Acoustics, 121(3):422-428, 1999.

[10] B.L. Clarkson and R.J. Pope. Experimental determination of vibration parameters required in the statistical energy analysis method. Journal of Vibration, Acoustics, Stress, and Reliability in Design, 105(3):337-344, 1983.

[11] J. Cordioli, V. Cotoni, and P. Shorter. Numerical investigation of the transmission loss of seals and slits for airborne sea predictions. SAE Technical Paper, 2009 .

[12] R. J. M. Craik. Sound transmission through buildings: using statistical energy analysis. Gower Publishing Company, 1996.

[13] J. Forssén, S. Tober, A. C. Corakci, A. Frid, and W. Kropp. Modelling the interior sound field of a railway vehicle using statistical energy analysis. Applied Acoustics, 73(4):307-311, 2012.

[14] A. K. Fung and E. B. Davis. Prediction of airplane aft-cabin noise using statistical energy analysis. The Journal of the Acoustical Society of America, 118(3):18471847, 2005.

[15] B. M. Gibbs, R. Cookson, and N. Qi. Vibration activity and mobility of structureborne sound sources by a reception plate method. The Journal of the Acoustical Society of America, 123(6):4199-4209, 2008.

[16] M. C. Gomperts and T. Kihlman. The sound transmission loss of circular and slit-shaped apertures in walls. Acta Acustica united with Acustica, 18(3):144-150, 1967.

[17] AEA group. AEA energy \& environment (2008). discussion report: EU ecolabel for refrigeration. Commission of the European Communities network.

[18] C. Hopkins. Sound insulation. Butterworth-Heinemann, 2012.

[19] ISO ISO. 3745, acousticsdetermination of sound power levels of noise sourcesprecision methods for anechoic and semi-anechoic rooms. International Organization for Standardization, 2003.

[20] J.Y Jeon and J. K. Ryu. Allowable noise levels of residential noises. In INTERNOISE and NOISE-CON Congress and Conference Proceedings, volume 2006, pages 1949-1955. Institute of Noise Control Engineering, 2006.

[21] K. Larson. Can you estimate modulus from durometer hardness for silicones. Dow Corning Corporation, 2016. 
[22] A. Le Bot. Foundation of Statistical Energy Analysis in Vibroacoustics. OUP Oxford, 2015.

[23] A. Le Bot and V. Cotoni. Validity diagrams of statistical energy analysis. Journal of Sound and Vibration, 329(2):221-235, 2010.

[24] Lu and Leo K.H. Optimum damping selection by statistical energy analysis. Journal of Vibration and Acoustics, 112(1):16-20, 1990.

[25] R.H. Lyon and R. G. DeJong. Theory and application of statistical energy analysis. Butterworth-Heinemann, 1995.

[26] S. Mathiowetz and H.A. Bonhoff. Interface mobilities for characterization of structure-borne sound sources resiliently mounted via multiple contact points. Journal of Sound and Vibration, 332(22):5789-5803, 2013.

[27] A.R. Mayr and B. M. Gibbs. Approximate method for obtaining source quantities for calculation of structure-borne sound transmission into lightweight buildings. Applied Acoustics, 110:81-90, 2016.

[28] M. Moeller, M. Gmerek, and A. Nagi. Power transfer functions for aircraft statistical energy analysis model validation. In 15th AIAA/CEAS Aeroacoustics Conference (30th AIAA Aeroacoustics Conference), page 3389, 2009.

[29] C. T. Musser, J. E. Manning, and G. C. Peng. Predicting vehicle interior sound with sea. Sound \& Vibration, 46(12):8, 2012.

[30] M. P. Norton and D.G. Karczub. Fundamentals of noise and vibration analysis for engineers. Cambridge university press, 2003.

[31] Supplementing Directive 2010/30/EU of the European Parliament and of the Council with regard to energy labelling of household refrigerating appliancesn. Official journal of the european union. Commission communication in the framework of the implementation of Commission delegated Regulation (EU) No $1060 / 2010$.

[32] B.A.T. Petersson and B.M. Gibbs. Towards a structure-borne sound source characterization. Applied Acoustics, 61(3):325-343, 2000.

[33] V. Phong and D. Papamoschou. High frequency acoustic transmission loss of perforated plates at normal incidence. The journal of the acoustical society of America, 134(2):1090-1101, 2013.

[34] S. Sato, J. You, and J. Y. Jeon. Sound quality characteristics of refrigerator noise in real living environments with relation to psychoacoustical and autocorrelation function parameters. The Journal of the Acoustical Society of America, 122(1):314-325, 2007.

[35] P. Schevenels, P.J.G. van der Linden, and G. Vermeir. An inverse force measurement method to determine the injected structure-borne sound power from an installation into a building element. Building Acoustics, 17(3):199-219, 2010. 
[36] M. M. Späh and B. M. Gibbs. Reception plate method for characterisation of structure-borne sound sources in buildings: Assumptions and application. Applied Acoustics, 70(2):361-368, 2009.

[37] ASTM Standard. E1050-12: Standard test method for impedance and absorption of acoustical materials using a tube. Two Microphones, and a Digital Frequency Analysis System, 2012.

[38] SR Standard. EN ISO 10534-2, determination of sound absorption coefficient and acoustic impedance with the interferometer.

[39] T. Wang, S. Li, S. Rajaram, and Nutt S.R. Predicting the sound transmission loss of sandwich panels by statistical energy analysis approach. Journal of Vibration and Acoustics, 132(1):011004, 2010.

[40] R. Zarate, E. Matus, M. Lopez, and L. Ballesteros. Design of quieter kitchen appliances: Sound pressure level modeling and validation of a household refrigerator using statistical energy analysis. In Proceedings of Meetings on Acoustics 173EAA, volume 30, page 030009. ASA, 2017. 